\title{
Study on Major Issues Concerning the Implementation of the Online Game Shutdown System-With an Emphasis on Examples of Korea
}

\author{
Sung Wook Choi \\ Sahmyook University, Seoul, Korea
}

\begin{abstract}
This study is conducted on the special provision of the Korean government to prevent youths' addiction to online games. Judging that the youths' addiction to online games is serious, the Korea government made a legal provision to control the phenomena of youths' online game addiction. At that time, there were lots of conflicting opinions in the course of implementation of the related governmental act. The purpose of this study is investigating what conflicting opinions there were in the course of the legislation and also the fundamental cause of the opinion confliction and the countermeasures thereby. Especially, it is noteworthy that two departments of the government had different legal approaches toward the issue. Thus, this study will present an affordable suggestion for other countries which have youths' online game addiction problems.
\end{abstract}

Keywords: online game, shutdown system, game addiction, Korea government, legal regulation

\section{Introduction}

It is already 15 years since the internet online game service began on a full scale in Korea. The development of information technology has led the growth of the online game industry which has been settled as the axis of an industry with export competitiveness. However, there have been critics about the adverse effect of online games in the society (Song, 2005). Thus, there have been conflicting opinions about online games in Korea. The online game industry is expected to be one sector of software industry which will become the axis of Korean economy, but it is blamed for a major cause of the lack of sleep, the deterioration of school learning, and violence of youths due to game addiction. Especially, there are still controversies over the legal regulation for the purpose of protecting youths and also over the regulation mainly targeting youths. On May 19, 2011, Korea added articles (26 articles) for a shutdown system by revising the Youth Protection Act, a so-called Cinderella Act, so as to prevent youths' game addiction. The new stipulation began to be implemented in November 2011 and had been enforced since 2012 after a period of education. The main content of the shutdown is banning youths of younger than 16 years of age from internet games for six hours from midnight to six o'clock in the morning. Thus, internet game service providers shall shutdown their service to youths, younger than 16 years old, through identifying the age and identity of youths during that period of

Sung Wook Choi, Ph.D., assistant professor, Department of Management Information Systems, Sahmyook University, Seoul, Korea.

Correspondence concerning this article should be addressed to Sung Wook Choi, Department of Management Information Systems, Sahmyook University, Seoul, Korea. 
time. This regulation is applied first to PC internet online games and PC package games accessible from CD, wherein all games for which personal information is to be requested are applied to the shutdown regulation, and also applied to games for which personal information is not requested but an additional charge is requested (Doosan all Kinds of learning).

The youths' online games were banned during the night hours because there frequently occur various youth problems such as ADHD (attention deficit hyperactivity disorder), cyber crimes, schooling deterioration, domestic discords, etc.(Kocca, 2015). as the internet addiction of youths is becoming more serious day by day. According to reports on the internet addiction in 2014, the risk group by age showed 5.6\% children (143,000 persons), $12.5 \%$ of youths $(768,000)$, and $5.8 \%$ of adults $(1,711,000)$. The youths' internet addiction showed the highest risk by age (National Information Society, 2015). The sign of danger about the youths' internet addiction was continually reported from mid 2000's. According to the investigation of internet addiction in 2008, about $2.3 \%$ of children and youth, aged between 9 and 19, that is, 168,000 were in the highest risk group and about 12\% of them, 860,000 were assumed to be in the potential risk group. The figures of youths' internet game addictions must draw attention because the adverse effects of internet addictions including youths' learning deterioration are becoming greater and extensive with time (Jang, 2010).

The shutdown regulation, legislated because of such problems, was faced with a lawsuit that it is unconstitutional in 2014, but it was judged to be constitutional by the Constitutional Court, so it is being settled as an internet game culture. However, this new system has been in controversy from the start till now because there were sharp conflicting opinions about the shutdown. Therefore, this study investigates the fundamental causes of the conflicting opinions and presents the direction in which the shutdown system should develop in the future.

\section{Controversy Over Banning of Youths’ Night Internet Game}

\section{Pros for the Ban on Youths' Night Internet Game}

Pros claim that most of the internet addicts are also internet game addicts. Many of internet addicts spend all days playing games, and some serious addicts even fall into illusion thinking the world of a game as the real one. Considering examples of excessive addiction like that in the perspective of medicine, there is a medical view that the brain structure of drug addicts is similar to that of online game addicts. According to the result of study by Professor Sangeun Kim's team, the excessive users of internet games showed a higher impulse than ordinary users and more cerebral activities than normal people. This fact shows that internet severe game addicts and cocaine addicts have similar cerebral neurological mechanisms. Doctor Daejin Kim emphasized that internet game addictions can damage the brains of youths and make them lose their self control, thus exposing them to a danger of worsening their health. Namely, youths' game addictions can hinder their learning and also harm their health due to lack of sleep (Jang, 2010).

In knowledge of this danger, it is difficult to get out of online game addiction. If it is possible for individuals to avoid such a danger on their own, the addiction would not have been a social big problem like this. This shows that online game addictions cannot be relieved on addicts' own effort. Dr. Sangeun Kim's study team approaches internet game addictions in the perspective of medical disease. Sangeun Kim's study team made a PET (positron emission tomography) analysis of 20 internet game players who are excessive players and ordinary players. As a result, those playing online games excessively are lower in the operation of their functions of making rational decision and impulse-controlling than ordinary game players. So, there is a high possibility that their lower functioning can have effect on their rational decisions and emotional controls. There is a high possibility that this 
deterioration and adverse effect will have very negative effect on the change of youths' personalities, weakening their endurance, and on the formation of their values. If this trend becomes worse, it can result in depression and other serious problems. And there is one serious problem that needs attention: online game addicts do not recognize their addiction. When recognizing their addiction, they can cope with it for themselves , but they do not recognize it, they do not process medical treatments for themselves (Kim, 2010). Positive treatments should be given at the beginning of online game addiction as it is true to all types of diseases. It is difficult to give such addicts treatments in the beginning because their addiction is not recognized early. There is a high possibility that the internet game addiction will become worse if the opportunity to treat addiction in the beginning is missed. So, in such a case, prevention is more important than treatment. Considering the serious status of youths' game addictions in Korea, it is important to give positive treatments in the beginning and to prevent youths' game addictions.

So, pros for the shutdown regulation claim that youths' night online games should be regulated by law because they cannot perform positive treatments for themselves and follow the prevention system.

\section{Cons Against the Ban on Youths’ Night Internet Game}

Cons claim that the ban is limiting the fundamental rights of people. Namely, the regulation policy of government on the online games is limiting the fundamental rights of people. Their view is that the governmental regulation on the fundamental rights of people concerning the use of game violates the fundamental rights of people. Viewed from this perspective, the shutdown system can violate the right for equality, too, because there are found no regulation systems on online game in other countries. From the perspective of online game users in this global age, only Korea has regulations on online games, and it is against the right for equality.

There presented an issue about the suitableness of the legal shutdown system. The Youth Protection Act itself aims at controlling harmful media, but there can be controversy over whether the online game itself is a harmful medium. Their view is that the online game itself is not a problem, but the addiction from online games is a problem. As mentioned above, because addiction is not caused in nature by the online game itself, they claim that it is not suitable to solve the addiction problem through regulations (Jang, 2010).

There are many opinions that it is difficult to reap substantial positive results from the legal regulation because there are discussed informal methods to play online games during the banned hours by taking advantage of loopholes of the current regulation. One of the reasons that plays of online games can be active during the banned hours is that there are no specific punishment references for violations. Additionally, there is a high possibility that youths who are incomplete in the formation of their values can try to play online games during the banned hours by thinking that it will be safe if they are not caught. This trend can give various negative effects to youths in the process of making decisions. For example, there is a high possibility that they steal other's personal information to enjoy their online games during the banned hours without the sense of committing a crime.

The final reason is the government's claim that it is nurturing and promoting the contents industry including the game industry. Considering that the online game industry can produce a large profit in comparison with the initial investment in the game industry, the regulation on the online games is rather an alienation from the government policy to promote the contents industry. So, the regulation can result in the shrinking of the game industry, exerting an adverse effect on the creation of incomes of national economy. Especially, according to a survey, the online game industry is large in scale some times more than exports of Korean movies. Considering this, a more serious approach toward the online game regulation and systemic complements should be made in the view of promoting the contents industry. 


\section{Controversy Over Regulation Methods and Measures}

\section{Conflicts Between Departments of Government About Shutdown}

The so-called Cinderella Act is the nickname of the Shutdown System which is the formal legal name. The nickname, Cinderella, was given because youths' online games are banned from midnight to 6:00 am, as Cinderella in a fairy tale is released from magical grip at midnight. At that time, the Ministry of Gender Equality and Family pursued the revision of the Youth Protection Act in consideration of the information stated above. However, the Ministry of Culture, Sports, and Tourism in charge of the online game industry opposed the revision of the act in its judgement that the revised act can be an excessive regulation which can have a negative effect on the contents industry. So, the Ministry of Culture, Sports, and Tourism tried to make another revision of the act, causing social controversy (Kim, 2010). The reason why the two different revisions were promoted was due to the differences in opinion and objective between the two ministries. The Ministry of Gender Equality and Family whose most important policy objective is the protection of youths and the Ministry of Culture, Sports, and Tourism whose major policy objective was to secure competitiveness of the online game industry through the development of the industry which were naturally different in their opinion.

Looking at the process of promoting the different revisions between the two ministries, the Ministry of Gender Equality and Family passed the revision draft of the Youth Protection Act at the Standing Committee of the National Assembly on April 21, 2011. However, the Ministry of Culture, Sports, and Tourism submitted its revision draft of the Game Industry Promotion Act to the National Assembly on April 22, 2011 (Nam, 2010). Looking at the draft submitted by the Ministry of Culture, Sports, and Tourism, its major point was to ban new access to online games after midnight, namely, not banning users who are already using online games. This was the main issue. The Ministry of Culture, Sports, and Tourism claimed that there is a possibility that the draft of the Ministry of Gender Equality and Family violates the principle of excessive prohibition under the Constitutional Law.

The Ministry of Culture, Sports, and Tourism claimed that there is a high possibility that the limitation of youths' fundamental rights, presented by the Ministry of Gender Equality and Family violates the Constitutional Law, because the ministry viewed that the duty of protecting youths belongs to their parents and guardians, so the ministry viewed that it is suitable for their parents and guardians to choose the banning hours for online games, so the limitation on youths' online games is the limitation on their fundamental rights and there is no possibility that the limitation violates the Constitutional Law. Thus the ministry claimed that its draft is more suitable. However, the Ministry of Gender Equality and Family claimed that the draft of the Ministry of Culture, Sports, and Tourism cannot be a suitable one because it targets only at the growth of the online game industry. The ministry claimed that because the various policies and systems which target only at the promotion of the game industry have deteriorated youths' online game addictions, the draft of the Ministry of Culture, Sports, and Tourism cannot be a fundamental solution because it is a partial approach. The ministry claimed that the revision draft of the Ministry of Culture, Sports, and Tourism has too many loopholes. For example, if youths have accessed to online games by 23:59, they can continue playing online games till the morning of the following day. Also, as mentioned above, if youths use adults' IDs, there is no way to ban their access to online games (Nam, 2010). In fact, there are serious problems that youths use IDs of their brothers and parents. Especially, there is a view that the Ministry of Culture, Sports, and Tourism has not changed its measures against the excessive use of online games since 2005 and hasn't been active to cope with the problem. So, the Ministry of Gender Equality and Family claimed that the problem of youths' online game addiction should be addressed with more positive measures. 


\section{Controversy Over Excessive Regulation and Double Regulation}

Therefore, it is proper to look at the opinions of people engaged in the related industries. People engaged in the online game industry and in the related contents business view that the revision drafts of both ministries are almost same. If a ban on online game is legislated, related businesses will is affected. And if the two ministries pass two different revisions, it would mean that related businesses would be regulated doubly. So, opinions were drawn that a reasonable revision should be made because the different revisions of the two ministries would be a double and excessive regulation. Many people engaged in related businesses claimed that online games should be an object of regulation but a national nucleus competitive part of the industry as the acts are to be revised. Because if the revision drafts of the two ministries are doubly applied to the industry, the online game industry, which is growing, will be radically shrunk, the related businesses were more sensitive to the revisions.

Now, there needs to look at the overseas reactions to the situation of Korea at that time. The International Game Industry Forum and other various conferences took the related revisions to ban online games in Korea as an issue. They showed great interest in the fact that Korean government takes the lead in the regulation on the online game industry. The reason why people overseas showed lots of interest in the Korean movement was the change of global online game market because the growth rate of the online game market in Korea was dropping in comparison with that of China in 2011. Hence, because if the revisions are doubly and excessively applied, the market competitive rates will show more difference, there was shown lots of interest in the prospect of the online game industry from overseas and locally as well. According to related data, the online game market was expected to rise $50 \%$ in comparision with that of 2008 . However, it was surveyed that the online game market in Korea grew about $30 \%$. Because there was a $20 \%$ difference - a big difference-in the growth rates, the environment of the online game industry in Korea roused a lot of interest locally and overseas as well. Because the size of the online game market of China became already larger than that of Korea in 2008, the local online businesses felt a sense of crisis. Unlike the situation in which China was importing online games from Korea due to the online game competitiveness of Korea, Korean businesses were importing online games from China. So, Korean online game businesses were in more tense about the regulation guidance (Nam, 2010). At that time, the second new work of Starcraft Game, which roused a sensation around the world, was released and they had to compete with Japanese Nitendo game, so Korean online businesses complained about the tough situation.

In the situation, Korean online game businesses presented a problem of equality about the revision movement because the revisions targeted at only Korean businesses, namely, because the revision drafts targeted at only the online game businesses providing services in Korea, the complaint was natural. In addition, they complained about the reason why only the online game among other various games is targeted at. People engaged in Korean online game businesses continually suggested the building up of environment to solve the online game addiction of youths through a self-regulatory system such as Online Game Fatigue System (Seong, 2010).

\section{Conclusion}

The shutdown system of Korea, discussed as above, developed the various differences in interests a social issue. Despite the big controversy, the State Council of Korea passed the revision in November 2011 as Article 26 of Youth Act. Afterwards, 13 online game businesses and three parents of youths, aged less than 16, presented a lawsuit to the Constitutional Court, and finally, it was judged to be constitutional on April 26, 2014 (Lee \& Jeong, 2014). The shutdown system needs to be improved to have its identity and be approved by youths and the public. The businesses claim that suitable measures and the effect of the law should be improved. Still, it is found that 
youths are enjoying online games after midnight. It is not easy to determine that the law is suitable to the current situation of Korea.

The online game industry of Korea is an industry which can contribute greatly to the economy of Korea with its potential power of development and competitiveness. Actually, the income structure of the online game industry of Korea has greater competitiveness than the average income structure of other industries. Hence, if viewing from this perspective of economic efficiency, any unconditional regulation is not the right approach. A way should be sought out to secure superior competitiveness of the industry within the scope in which online games do not hinder the healthy growth of youths.

The government should be agony to develop policies to prevent youths' online game addiction problems. The development of such policies should be promoted positively such as medical treatment, not just a negative approach. Education should be given widely to publicize in advance that online game addictions can cause side effects. Especially, youths who are addicted to online games and their families should be educated so that the addicts can be treated actively and recover. Together with systematic approaches of the government, youths, and their parents should help to view the leisure culture and game culture as positive cultures, not negative ones, and to enjoy such cultures.

Efficient and practical measures rather than fruitless regulations should be provided with continual monitoring and should be developed to protect youths from game addictions or harms.

\section{References}

Jang, D. (2010). Is there no problem with revision of youth protection law? ET New. Retrieved from http://www.etnews.co.kr

Jang, E. (2010). Youths game addiction is serious fatigue system, shutdown system effectless, medical today. Retrieved from http://www.mdtoday.co.kr/

Kim, G. (2010). Controversy over cinderella law, ban on youths' night game. Chosun.com. Retrieved from http://www.chosun.com/

Kim, S. (2010). Should youths' internet games be banned after midnight? Korea Economy Daily.

Korea Creative Content Agency: Kocca. (2015). Study on general measures for game addiction, Volume 1, General Report

Lee, Y., \& Jeong, J. (2014). Game shutdown, not a excessive regulation. Constitutional, Hankook Ilbo. Retrieved from http://hankookilbo.com

Nam, S. (2010). “Cinderella law”, a magic law with regulations, Porbes Korea, SisaMedia, Korea Joong Ang Dail. Retrieved from http://joongang.joins.com/

National Information Society. (2015). Ministry of Science, ICT and Future Planning. Survey on Internet Addiction in 2014.

Naver Knowledge all Kinds of learning (Doosan all Kinds of learning) . Retrieved from Shutdown, in Naver Dictionary. Retrieved from http://terms.naver.com/entry.nhn?docId=1381182\&cid=40942\&categoryId=32854

Seong, W. (2010). Government bans on youths’ night games. Daily Economy. Retrieved from http://www.enewstoday.kr/

Shin, J. (2013). Review on shutdown to prevent youths' game addiction. Law Study Institute of Gyeongsang National University 21(3), 119-147.

Song, W. (2005). How to help youths have deep sleep-Ban on youths' online games. A Warm Digital World, Academic Information, the Information Korean Telecommunication Policy Review, 5. 